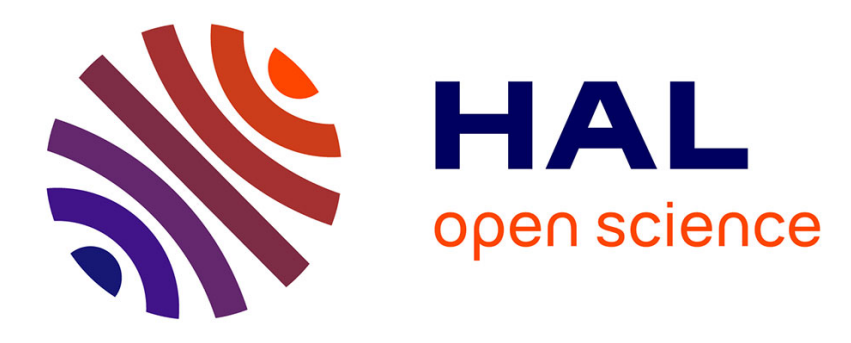

\title{
IONIZATION MODEL FOR NICKEL-LIKE GOLD
}

\author{
M. Busquet, Julien Bruneau
}

\section{To cite this version:}

M. Busquet, Julien Bruneau. IONIZATION MODEL FOR NICKEL-LIKE GOLD. Journal de Physique Colloques, 1986, 47 (C6), pp.C6-333-C6-337. 10.1051/jphyscol:1986641 . jpa-00225885

\section{HAL Id: jpa-00225885 https://hal.science/jpa-00225885}

Submitted on 1 Jan 1986

HAL is a multi-disciplinary open access archive for the deposit and dissemination of scientific research documents, whether they are published or not. The documents may come from teaching and research institutions in France or abroad, or from public or private research centers.
L'archive ouverte pluridisciplinaire $\mathbf{H A L}$, est destinée au dépôt et à la diffusion de documents scientifiques de niveau recherche, publiés ou non, émanant des établissements d'enseignement et de recherche français ou étrangers, des laboratoires publics ou privés. 


\title{
IONIZATION MODEL FOR NICKEL-LIKE GOLD
}

\author{
M. BUSQUET and J. BRUNEAU \\ Commissariat à I'Energie Atomique. Centre d'Etudes de \\ Limeil-Valenton, B.P. $n^{\circ}$ 27, F-94190 Villeneuve-Saint-Georges, \\ France
}

\begin{abstract}
Résumé - A l'aide d'un modèle très simplifié, mais qui permet une bonne interprétation des spectres expérimentaux obtenus sur l'or, nous mettons en évidence l'importance des transitions souvent considérées comme faiblement importantes : cascades et transitions "horizontales".
\end{abstract}

Abstract - With a very simplified model, but which allow some understanding of the experimental spectra obtained on gold, we show the importance of frequently discarded transitions : cascades and $\Delta_{n}=0$ transitions.

\section{Introduction}

Among various scheme proposed for population inversion, the one called "collisionnal excitation pumping" has lead the design of the LLNL experiment'. Neon-like ions were used. For the same scheme S. MAXON, P. HAGELSTEIN et al ${ }^{2}$ have suggested the use of nickel-1ike $t$ in $\left(\mathrm{Sn}^{22+}\right.$ ) in a gas puff experiment and Eu ${ }^{35+}$ in a laser experiment ${ }^{4}$. Nickel-1ike gold ions have been studied in laser plasmas ${ }^{3}$ and can be used for the same purpose. Study of them is also worthwile for temperature and density diagnostic and for checking of simplified lonization models.

Before we build an extensive population model for gold ionized 49 to 52 times, we have studied with a more simple model the effect of accounting for cascades (or dielectronic recombination) and $\Delta n=0$ transitions. These transitions allow some understanding of typical feature of experimental gold spectra.

Electronic structure of ions

We first recall briefly the electronic structure of Nickel-1ike (Au ${ }^{+}$), Cobalt-1ike $\left(\mathrm{Au}^{52^{+}}\right)$and Copper-1ike ions $\left(\mathrm{Au}^{50^{+}}\right.$).

N1cke1-like ground state is a closed she11 $3 p^{6} 3 d^{10}$, of which either $3 d$ or $3 p$ electron can be easily excited. The optically forbidden 3d-4d transition has a rather high collisionnal excitation rate; the $3 \mathrm{~d}^{9} 4 \mathrm{~d}$ metastable levels can also be populated through desexcitation from the $3 \mathrm{~d}^{9} 4 \mathrm{f}$ and $3 \mathrm{p}^{5} 3 \mathrm{~d}^{10_{4}} \mathrm{~s}$ levels. This 1 eads to a possibility of population inversion with the $3 \mathrm{~d}^{9} 4 \mathrm{p}$ levels which are rapidly depopulated by spontaneous emission. 
Similar transitions are found in $\mathrm{Au}^{50^{+}}$, but with one "spectator" electron which yields transition arrays instead of isolated lines. But the excited levels are more closely coupled and less subject to non equilibrium population, due to the proximity of the ionization limit. In $\mathrm{Au}^{52^{+}}$, transitions arrays are the consequences of the one more hole in the $3 \mathrm{~d}$ subshell.

Seven hundreds of optically allowed lines had been computed by D. PAIN and J. BAUCHE ${ }^{3}$ distributed among five successive ionization stages. For this study, one of us (J.B.) with his own multi-configuration Dirac Fock (MCDF) program, has compute about thirty thousands transitions, both allowed and forbidden, distributed among four iondzation stages ( $\mathrm{Au}^{49+}$ to $\mathrm{Au}^{52+}$ ), for the $\mathrm{n}=3$ to $\mathrm{n}=4$ electronic jump. The wavelengths of the $\mathrm{Zn}-1$ like $3 \mathrm{~d}_{5 / 2}-4 \mathrm{f}_{7 / 2}$ transitions has been corrected by a factor of 1.004 as all correlations has not been accounted for in the MCDF runs for these lines.

The synthetic spectra shown further use the MCDF values.

\section{Accounting for low-rate transitions}

To demonstrate the effect of new transitions, even with low rates, added to a given population model, we shall present the case of a very simple CR model. The reader will understand that the conclusion stays for a more extensive model.

In the "coronal equilibrium" approximation, an excited level ( 1 ). is populated through direct collisionnal excltation from the ground state ( 0$)$. Its population is found by balancing excitation rate with spontaneous radiative decay: $N_{i}=N_{0} C_{o i} /\left(\Sigma A_{i j}\right)$. The line intensity is then $I_{10}=N_{i} A_{i o} h \nu=N_{0} C_{o i} h \nu A_{10} /\left(\Sigma A_{i j}\right)$. Using the collision strength $f_{o i}$, it comes :

$$
I_{\text {io }}=N_{0} \cdot n_{e} B T_{e}^{\frac{1}{2}} \quad F_{o f} B R_{i} \exp \left(-h \nu / k T_{e}\right)
$$

where $B=3.2 \times 10^{-6} \mathrm{eV}^{\frac{1}{2}} \mathrm{~cm}^{3} \mathrm{~W}$, and $B R_{i}$ is the branching ratio $\left(B R_{1}=A_{10} / \Sigma A_{i j}\right)$.

In "LTE" approximation one will found $I_{10}=N_{0} / \omega_{0} C(h \nu)^{3}$ gf exp $\left(-h v / k T_{e}\right)$ where $\mathrm{C}=4.32 \times 10^{7}{\mathrm{~W} . e V^{-3}}^{-}$

These two widely used models yield both line intensities proportionnal to the oscillator strength, at least for the brightest 1 ine where $\overline{\mathrm{g}} \approx$ constant. They cannot reproduced for example the experimental line ratios for the three components of the $3 \mathrm{~d}-4 \mathrm{p}$ transition of Nickel-1ike gold Au $51+$ (cf. Fig 1).

In a complete population model, the excited level (i) is also populated by $\Delta n \neq 0$ transitions, (which total rate will be noted $Q_{1}$ ), and by downward transitions (cascades, dielectronic recombination,...) which total rate will be noted $P_{1}$. Depopulating transitions are collisionnal desexcitation towards ground state (with rate $\mathrm{C}_{10}$ ), $\Delta \mathrm{n}=0$ transitions (with rate $Q_{i}^{\prime}$ ) and excitation ionization that we shall neglect in this study.

The Iine intensity is then given by

$$
I_{10}=N_{0} \frac{C_{01}+P_{i} Q_{1}}{C_{10}+A_{10} / B_{1}+Q_{1}} \quad C \quad f_{10}(h v)^{3}
$$


Due to the large number of energy levels (106 in $\mathrm{Au}^{5 \mathrm{~L}^{+}}$) of the complex with an electron excited on the $n=4$ shell, assuming a constant value for $Q^{\prime}{ }_{i}$ and $P_{i}$ is a reasonnable approximation. In order to demonstrate the effects of the added transitions, we shall also assume that $P_{1}$ do not depend of the level (1).

We can now easily turn on and off these entrance and exit channels by changing the values of $P$ and $Q$. ( $Q^{\prime}$ is deduced from $Q$ by the detailed balance principle).

One can understand that, due to the $\Delta n=0$ transitions, (when $Q_{1}=0$ ).

OPENING NEW ENTRANCE CHANNELS TOWARDS SHORT LIVED LEVELS ENHANCES EMISSION OF THE "METASTABLE" LEVELS.

This yields better prediction of the $\mathrm{Au}^{51+} 3 \mathrm{~d}-4 \mathrm{p}$ lines (Fig 1). But a more impressive result is found on the $3 d-4 f$ array.

It has been shown in a previous paper ${ }^{3}$, that the experimental spectral shape of this array cannot be reproduced by convolution of a simple line profile with the Iine intensities deduced from their gf values. A phenomenological interpretation was that some satellite lines accompany each resonnance transition and give then a line profile with an extended $(150 \mathrm{~m} \AA)$ red wing ( $F i g 2)$.

The piling up of these red wings reproduce the experimental understructure of the $3 d-4 f$ array.

The simple CR model we have presented here, with the "coupling enhancement" of the low gf lines shows good construction of synthetic spectra (F1g 3).

However a reduced red wing ( $30 \mathrm{~mA})$ still seems worthwhile, and means that other lines or mechanisms have to be added (Fig 4).

\section{Conclusion}

The good agreement between experimental and synthetic spectra shows the importance of the cascades and $\Delta n=0$ transitions. Recalling that in some case $90 \%$ of the 3d - $4 f$ array emitted intensity is found in the understructure, it becomes unaffordable to neglect these transition for power losses estimation, Ionization/reconbination rates in ionization model and even detailed population model as it can dramatically change line intensity (or gain) ratios of different components of a same multiplet.

1 PRL, 54(2), 106 and 110 (Jan. 85)

2 JAP, 57(3), 971 (Feb. 85)

3 Physica Scripta, 31, 137 (1985)

4 JAP, 59(1), 293 (Jan. 85) 
FIG 1 experimental spectrum of the $3 \mathrm{~d}-4 \mathrm{p}$ array of gold (a), compared to synthetic spectra with only the $g f$ values (b), or with this CR model (c). Ionization stages included range from $\mathrm{Au}^{52^{+}}$to $\mathrm{Au}^{49+}$, with reduced population of 0.05 , $1 ., 0.04$ and 0.008 .
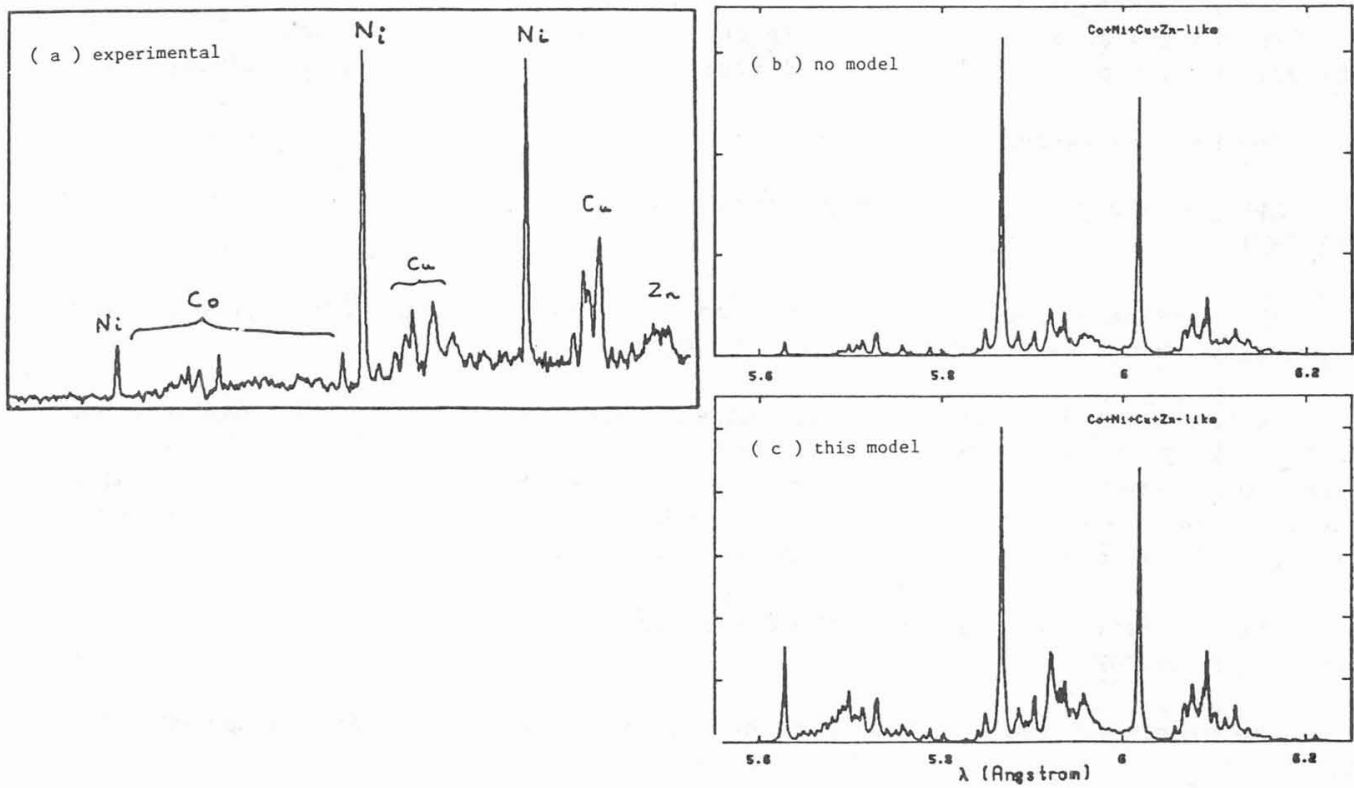

FIG 2 experimental spectrum of the $3 d$ - $4 \mathrm{f}$ array of gold (a), compared to synthetic spectra with only the gf values (b), or with a red wing $\left(\Delta \lambda=100 \mathrm{~m} \AA, P_{1 \text { ine }} / P_{\text {wing }}=0.3\right)$ added to each line $(c)$.
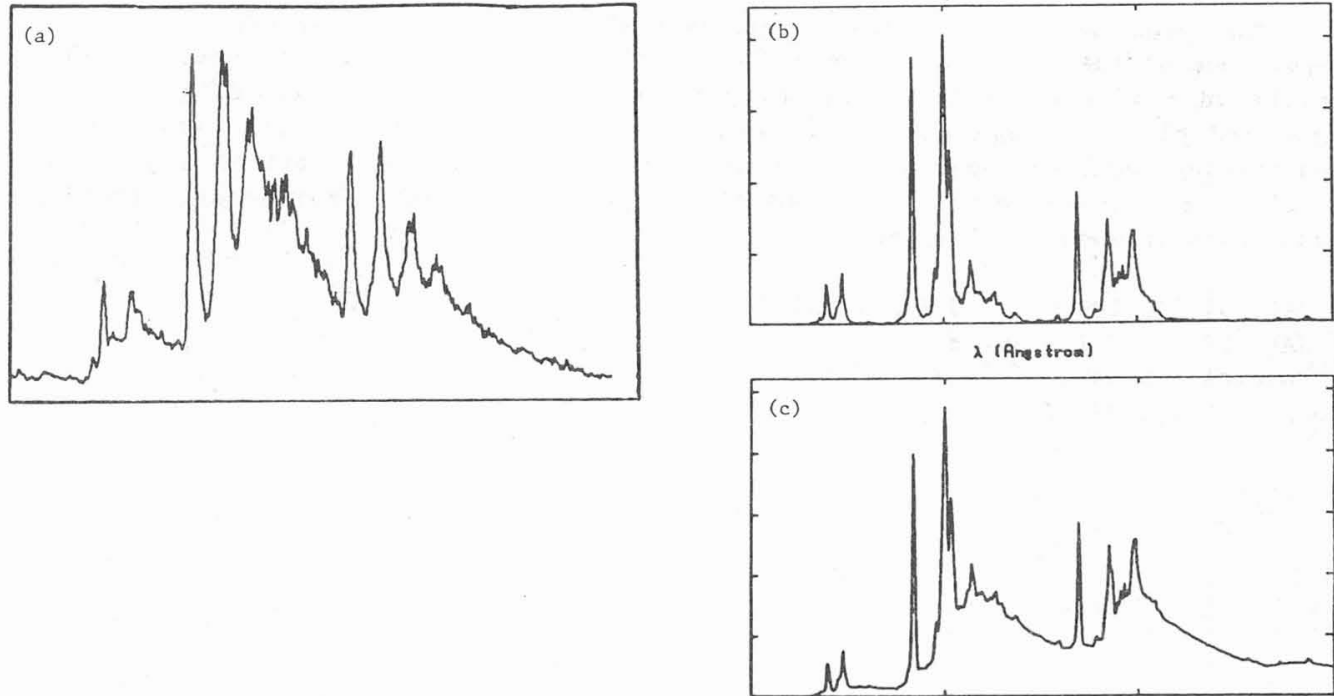
FIG 3 Synthetic spectra of the 3d - $4 \mathrm{f}$ array of gold obtained with this model. Populations are the same as in Fig 2. $P=Q=4.10^{11} \mathrm{~s}^{-1}$

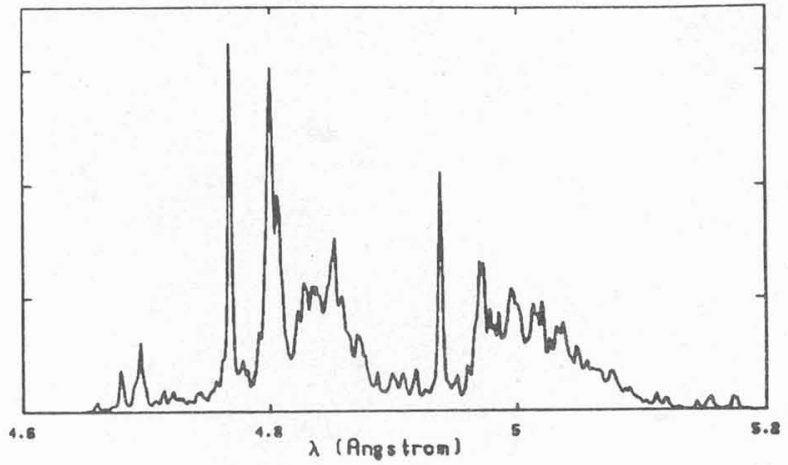

FIG 4 Same as Fig 3 but with a small $(30 \mathrm{~mA})$ red wing added.

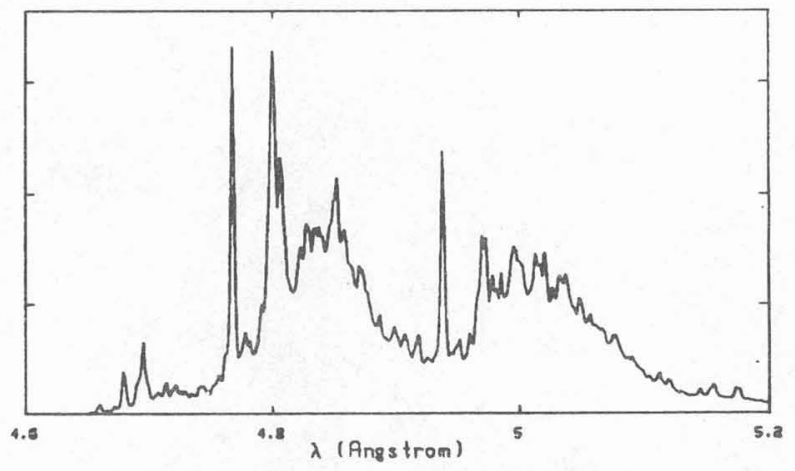

